\title{
Editorial: Learning Development 10 years on
}

\section{Andy Hagyard}

University of Lincoln, UK

John Hilsdon

Plymouth University, UK

\section{Stephanie McKendry}

Glasgow Caledonian University, UK

With the 10th ALDinHE conference about to take place in Plymouth, it seems timely to take stock of Learning Development (LD) in the UK. In our opinion, there is a lot to be optimistic about. Scholarly and research-based evaluation of activities is becoming the norm in the field, and discussion of the epistemological and pedagogical foundations of practice is increasingly necessary and visible. A quick glance at the contributions to this issue of the journal certainly supports this view. Case studies do more than share ideas and practice; they evaluate impact and consider implications. Many of the papers engage with profound theoretical questions or disseminate the outcomes of well-founded research. Some were commissioned by their institutions to investigate the subject matter or were established after successful funding bids to conduct their research.

This evident progress of research-based approaches in Learning Development offers opportunities for well-informed consideration of the nature and scope of the field. Is it a distinct academic discipline - the subject of one of the papers in this issue? Has Learning Development joined the academy in its own right or is it a minor offshoot of a wider or multidisciplinary approach such as Educational Research or Educational Development? Is it a profession, with a unique set of practices and an evidence-base to support them? How is it viewed from the outside? Do we need to work collectively to enhance both the visibility and the reputation of LD - whatever it may be? The fact that we are beginning to discuss these questions suggests a potential shift in our own consciousness at least; one that may be increasingly necessary given the wider political and socio-economic circumstances in which higher education finds itself. 
Helen Avery and Monne Wihlborg engage with even broader questions in their paper, examining the purpose or aims of higher education in general. They argue that the Scandinavian university sector is subject to contradictory objectives: higher education aims to promote a learner-centred, holistic, Bildung approach enabling learners to become independent, critical thinkers. Yet obligations towards instrumentalism, standardisation and the measurement of achievement against fixed standards, can result in purely procedural learning and the risk of alienated or disempowered learners. Their research suggests that academic staff are nonetheless able to create a space for learning and the negotiation of meaning and goals; an essential practice if education is to be framed in a wider discourse than that of 'productivity'.

Pat Hill and Amanda Tinker ask similar questions about the role of higher education and, more specifically, where Learning Development should sit within it. Whilst building a website to disseminate case studies of effective integration of learning development within curricula, they were able to investigate academic staff perceptions of skills development. Results were mixed, with some staff regarding such activity as an integral aspect of their programme and role, and others expressing more negative attitudes, perceiving LD rather narrowly as attempts to embed skills, and seeing such activity as patronising, unnecessary or 'remedial'. The development of the case study resource attempts to inform and, ultimately, persuade staff of the benefits and range of ways in which learning development can be successfully embedded.

Rhona Sharpe, Frances Deepwell and Patsy Clarke continue the exploration of the most effective location for support within an institution. Their developmental evaluation of the role of Student Support Coordinators (SSC) at Oxford Brookes University provides evidence of the value of embedded, faculty-based support. SSCs are increasingly able to participate within the broader learning and teaching community of their faculty. Their location has provided them with visibility, insight, stronger relationships with staff and, perhaps, increased legitimacy to students. Whilst the authors point to concerns about the 'firefighting' nature of the role, they argue for the potential to engage in proactive support interventions to facilitate retention.

Two other contributions make a strong case for the integration of skills development into core learning and teaching. In addition they highlight the need to facilitate that integration 
via technologies and the development of a range of resources and approaches to embedding skills. The embedding of skills is an aspect of Learning Development long acknowledged within the field; one that sits alongside other aspects of our practice, such as 'identity work', raising the confidence of learners so they can perceive themselves as legitimate participants within the academy. Helen Howard and Michelle Schneider report on a skills strategy that aims to support academic staff in incorporating skills development into teaching. The award winning Skills@Library lecturer webpages are an online portfolio of teaching resources designed to provide blended learning materials, lesson plans and workshops for use by academic staff. Neil Ford and Melissa Bowden discuss the opportunities presented by institutional change to embed information and academic literacies development and harness digital media. The co-location of librarians, learning technologists and language support specialists allow for greater collaboration and the creation of shared resources and a single, online presence for student support.

Our guest editorial by Andrea Raiker and David Mathew also discusses the need to battle silo mentalities. The editors of the Journal of Pedagogic Development believe that significant progress has yet to be made in understanding student learning in spite of the large body of research and discussion developed over the last two decades. They point to one particular finding however, that pedagogical development is as important a transformational shift for new academic staff as the development of graduate attributes is for learners.

Peter Samuels' contribution discusses one of our original questions - to what extent LD can be considered an academic discipline - using the case study of Educational Development, amongst others, for comparative purposes. Tackling the thorny issue of defining disciplinarity, Samuels argues that were LD to be perceived as a discipline rather than a movement, it might enable further development, collaboration with related fields and greater recognition as a conversational partner in the discourse of academia. Most interestingly, from an editorial perspective, is the conclusion that LD should begin to formalise the nature of research to strengthen validity and promote greater understanding of learning, rather than simply evaluating interventions with a necessarily self-selecting group of participants. Clarifying Learning Development's relationship to the more established field of Educational Development appears necessary and is hopefully beginning, not least with the cross fertilisation facilitated by our developing relationships 
with organisations such as SEDA and publications such as the Journal of Pedagogic Development.

Three of the contributions deal with issues relating to the uses of feedback in academic work. Although each examines feedback in a different context, in all three the role of affect and engagement are key themes. John Cowan's paper, 'Facilitating reflective journaling' offers an insight into wisdom accrued over three decades of practice in a wide range of $\mathrm{HE}$ roles. John's focus as an academic, a creator of learning resources and as a highly respected author has always been on the experience of students as learners and emphasises the powerful part played by affect and relationship in any learning context. Moreover, it is the development of students' capacity and confidence to self-assess that John's mode of facilitated self-reflection through journaling illustrates. He presents practical examples of how such reflective work can be promoted when acting as facilitator, especially through 'nudging' and the use of strategic 'feedforward' comments in emails accompanying responses to student journals.

Peter Day develops ideas associated with the power of feedback in student groups in a fascinating study of the 'art group crit'. He finds that widespread perceptions of the group crit are charged with emotion and fear, so that the 'supportive and bespoke dynamic intentions' of the activity are often undermined or lost. How then can we reduce such fears and make best use of the powerful potential for learning that is represented by the giving and receiving of peer feedback in groups settings? Day's conclusions stress the need to develop positive, respectful practices - genuine learning development activities for making the most of both feedback and participation in a group.

Continuing the theme of exploring feedback is Elizabeth Gaston's case study describing another highly innovative learning development approach. In her project formative feedback was given verbally, digitally recorded and then posted to the student in question. She followed the findings of an earlier study suggesting that brief, regular, formative feedback is more useful to students than summative reports. Addressing students' calls for more feedback, as expressed in the NSS returns, Gaston's approach also offers flexibility and control to students in that they own the recordings and can play and repeat them in their own time and in the comfort of their own environment. 
Our final two contributions demonstrate the value of student-centred approaches, whether that is through the development of learning videos, as in Caroline Cash and John Sumpter's case study, or in David Coghlan and Anne Graham Cagney's attention to learning processes via insider inquiry. Cash and Sumpter detail and evaluate the Intuitive Resources project: the development of a series of learning resources embedded within the curriculum of design courses. Videos were developed to complement face-to-face technical support with the provision of intuitive, non text-based instructional material accessible at the time, and on the platform preferred by individual students.

'Insider inquiry' is an approach to learning that focuses on direct experience of participation in activities in their real-world context. According to Coghlan and Cagney, developing skills associated with this mode of inquiry - i.e. individuals' awareness of their own learning processes - can be seen in terms of the notion of a threshold concept. In their paper, 'Multisensory Holistic Immersion', these authors argue that engagement by business students in the 'swampy lowlands' of their own part-time employment experiences can yield fruitful learning about how organisations work. This, they argue is important in 'transition from university life to the world of working in organisations'. Drawing upon work by Evered and Louis (1981) they take the view that iterative, practical, reflective learning - which they contrast with academic, propositional learning - is necessary for making sense of practice, and fosters an internalised self-awareness and an inquiring approach generally.

The contents of this edition of the JLDHE - the accounts of practice, the research and theorising - confirm our optimism that after ten years in existence, the Learning Development community and its association, ALDinHE, are both still growing and the field of practice is developing. Learning Developers know the potential for transformation that successful participation in HE can afford - to individuals and to society as a whole. We also know that the work of LD contributes significantly to students' persistence and success at university, whether via one-to-one tutorials, peer learning or group sessions or use of LD materials. We hope that university decision makers will heed the evidence so that universities, fulfilling their duty to widen participation in HE, invest appropriately in this area. When we look back in ten years time, we are confident that LD will have further established itself as a creative and productive force in higher education. 